\title{
Pharmacological and therapeutic potential of Cordyceps with special reference to Cordycepin
}

\author{
Hardeep S. Tuli • Sardul S. Sandhu • \\ A. K. Sharma
}

Received: 1 October 2012/ Accepted: 2 February 2013/Published online: 19 February 2013

(C) The Author(s) 2013. This article is published with open access at Springerlink.com

\begin{abstract}
An entomopathogenic fungus, Cordyceps sp. has been known to have numerous pharmacological and therapeutic implications, especially, in terms of human health making it a suitable candidate for ethno-pharmacological use. Main constituent of the extract derived from this fungus comprises a novel bio-metabolite called as Cordycepin ( $3^{\prime}$ deoxyadenosine) which has a very potent anti-cancer, antioxidant and anti-inflammatory activities. The current review discusses about the broad spectrum potential of Cordycepin including biological and pharmacological actions in immunological, hepatic, renal, cardiovascular systems as well as an anti-cancer agent. The article also reviews the current efforts to delineate the mechanism of action of Cordycepin in various bio-molecular processes. The study will certainly draw the attention of scientific community to improve the bioactivity and production of Cordycepin for its commercial use in pharmacological and medical fields.
\end{abstract}

Keywords Cordyceps militaris - Infection - Cordycepin · Mechanism · Pharmacological effect

\section{Introduction}

Medicinal mushrooms have been known for thousands of years to produce biometabolites which are used or studied

H. S. Tuli · A. K. Sharma $(\varangle)$

Department of Biotechnology, M.M.E.C.,

Maharishi Markandeshwar University, Mullana,

Ambala 133203, Haryana, India

e-mail: anibiotech18@gmail.com

S. S. Sandhu

Department of Biological Sciences, R. D. University, Jabalpur 482001, MP, India as possible treatment for diseases. Over two-third of cancer-related deaths could be prevented or reduced by modifying our diet with mushrooms, as they contain antioxidants (Borchers et al. 2004; Zaidman et al. 2005). Cordyceps have a history of medicinal use spanning millennia in parts of Asia ( $\mathrm{Gu}$ et al. 2007). The name Cordyceps has been derived from two Latin words, i.e., cord and ceps meaning club and head, respectively. Cordyceps militaris belongs to the phylum Ascomycota classified in the order hypocreales, as spores are produced internally inside a sac, called ascus (Wang et al. 2008). It is an entomopathogenic fungus having an annual appearance which often grows parasitically on lepidopteron larvae and pupae of insects and spiders. It normally inhabits on the surface of insects pupae in winters and leading to the formation of fruiting body in summers justifying its name as "winter-worm summer-grass".

Cordyceps has been found mainly in North America, Europe and Asia (Mains 1958; Winkler 2010; Panda and Swain 2011). In India, it is prominently found in subalpine regions of grassy lands of Himalayas commonly known as "Keera Ghas". Recently it has been reported from Sutol and Kanol villages of Chamoli district of Uttarakhand (Singh et al. 2010). The ethnopharmacological use of Cordyceps sinensis has been reported from western Nepal for the cure of different diseases like diarrhea, headache, cough, rheumatism, liver disease, etc. This herb is also referred as "Himalayan Viagra" or "Himalayan Gold" due to its broad clinical and commercial value (Devkota 2006). Cordyceps requires specific set of conditions for its growth and has small size; therefore, the large-scale collection of this mushroom is a daunting task. However, people within the age group 15-65 years including men, women, young boys and girls are the main collectors of this fungus and price for $1 \mathrm{~kg}$ of wild-collected mushroom in the market of 
Nepal varies from 30,000 to 60,000 Nepali Rupees while in India it costs about Rupees 100,000 (Sharma 2004). Past 5 years have seen tremendous exploitation of Cordyceps which has significantly reduced its wild occurrence (Negi et al. 2006; Winkler 2008). Efforts have been made to artificially cultivate this mushroom by surface and submerged fermentation techniques.

There have been a variety of pharmacologically active compounds (e.g., Cordycepin) reported from Cordyceps sp. Cordycepin (Fig. 1) has received much attention due to its broad-spectrum biological activity. It is known to interfere with various biochemical and molecular processes including purine biosynthesis (Fig. 2) (Overgaard 1964; Rottman and Guarino 1964), DNA/RNA synthesis (Fig. 3) (Holbein et al. 2009) and mTOR (mammalian target of rapamycin) signaling transduction (Fig. 4) (Wong et al. 2010). Cordyceps has been included as one of the growing numbers of fungal traditional Chinese medicine (FTCM) used as cures for modern diseases with many products available commercially. Due to recent advancements in pharmaceutical biotechniques, it is possible to isolate bioactive compounds from Cordyceps and make it available in powder as well as in capsular form (e.g., Didanosine). Cordyceps and its product have remarkable clinical health effects including action on hepatic, renal, cardiovascular, respiratory, nervous, sexual, immunological systems, besides having anti-cancer, anti-oxidant, anti-inflammatory and anti-microbial activities (Zhou et al. 2008; Wang et al. 2011; Lee et al. 2011a, b; Zhang et al. 2012; Patel and Goyal 2012; Yue et al. 2012).

Keeping in view of the above facts, the current review updates us with the recent research pertaining to Cordyceps and the bioactive compounds isolated from it; especially for its ethno-pharmacological use. The study brings together a variety of mechanisms of Cordycepin at one platform and more importantly the broad spectrum pharmacological, clinical or biological activities associated with Cordyceps.

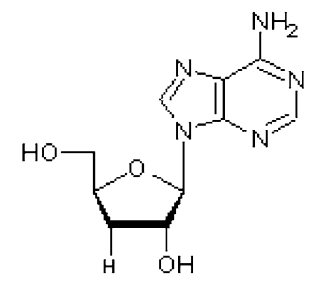

Cordycepin (3 deoyyadenosine)

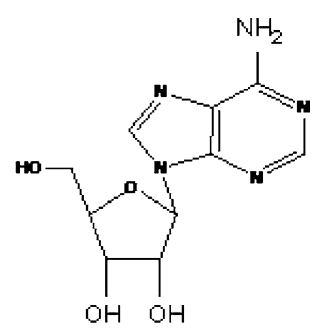

Aderosine
Fig. 1 The figure elucidates the difference in the chemical structures of bioactive compounds, Cordycepin and adenosine, produced by Cordyceps militaris

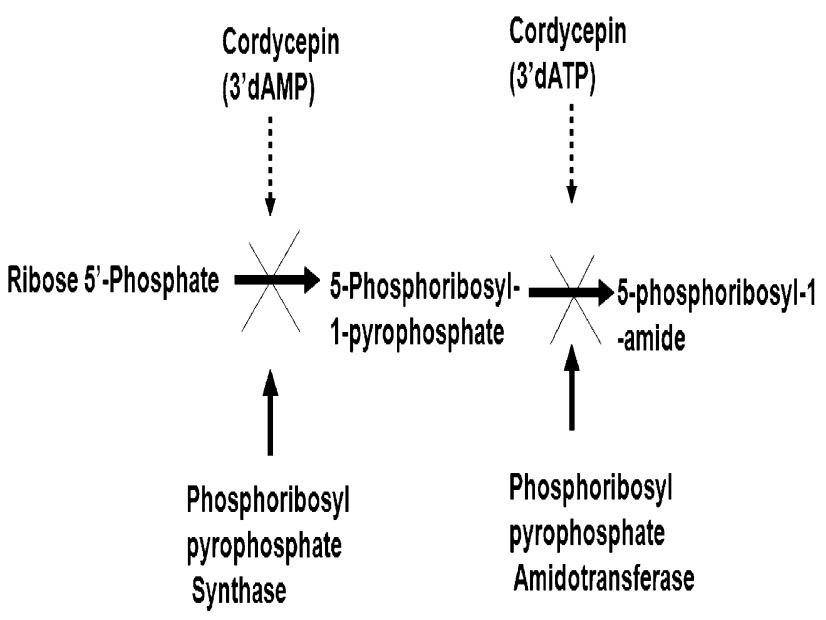

Fig. 2 The inhibitory effect of Cordycepin in mono- and triphosphate states on the enzymes, phosphoribosyl pyrophosphate synthase and phosphoribosyl pyrophosphate amidotransferase, involved in purine biosynthesis pathway

\section{Infection to the host}

Cordyceps usually infects insects at different stages of their development ranging from insect larvae to adult. Insect's epidermis is covered with a thick layer of cuticle (procuticle and epicuticle) which is also known as integument. Insect's integument comprises chitin, proteins and lipids. Beside this, it also contains variety of enzymes and phenolic compounds (Leger et al. 1991). Epidermis is formed by a single layer of epithelial cells followed by a thick layer of procuticle. Procuticle is differentiated into an inner soft part known as an endocuticle while the outer hard part is called exocuticle. Epicuticle and wax are known to constitute the outermost covering of the cuticle. This not only serves as a protective barrier against pathogenic organisms but also prevents water loss and acting as an interface between insect and its environment. Out of all these components, chitin which is a kind of heteropolysaccharide made with the polymerization of $N$-acetyl glucosamine through $1-4$ $\beta$-linkage constitutes an important structural component of insect's integument. Pathogen has to invade this tough integument covering to gain entry into the host.

Infection begins with the dispersion of fungus conidia on insect's surface. Once conidia get settled, they start germinating within a few hours under suitable conditions. To get protection from the environmental ultraviolet radiations, protective enzymes like $\mathrm{Cu}-\mathrm{Zn}$ superoxide dismutase (SOD) and peroxidases are secreted by the fungal conidia. These enzymes provide protection to the conidia from reactive oxygen species (ROS) generated due to UV rays and heat in the environment (Wanga et al. 2005). Besides this, conidia secrete certain hydrolytic enzymes like proteases, chitinases and lipases which lead to the dissolution of the integument and play a very important 
Fig. 3 The addition of Cordycepin as a Co-TP (Cordycepin tri-phosphate) leads to transcriptional termination

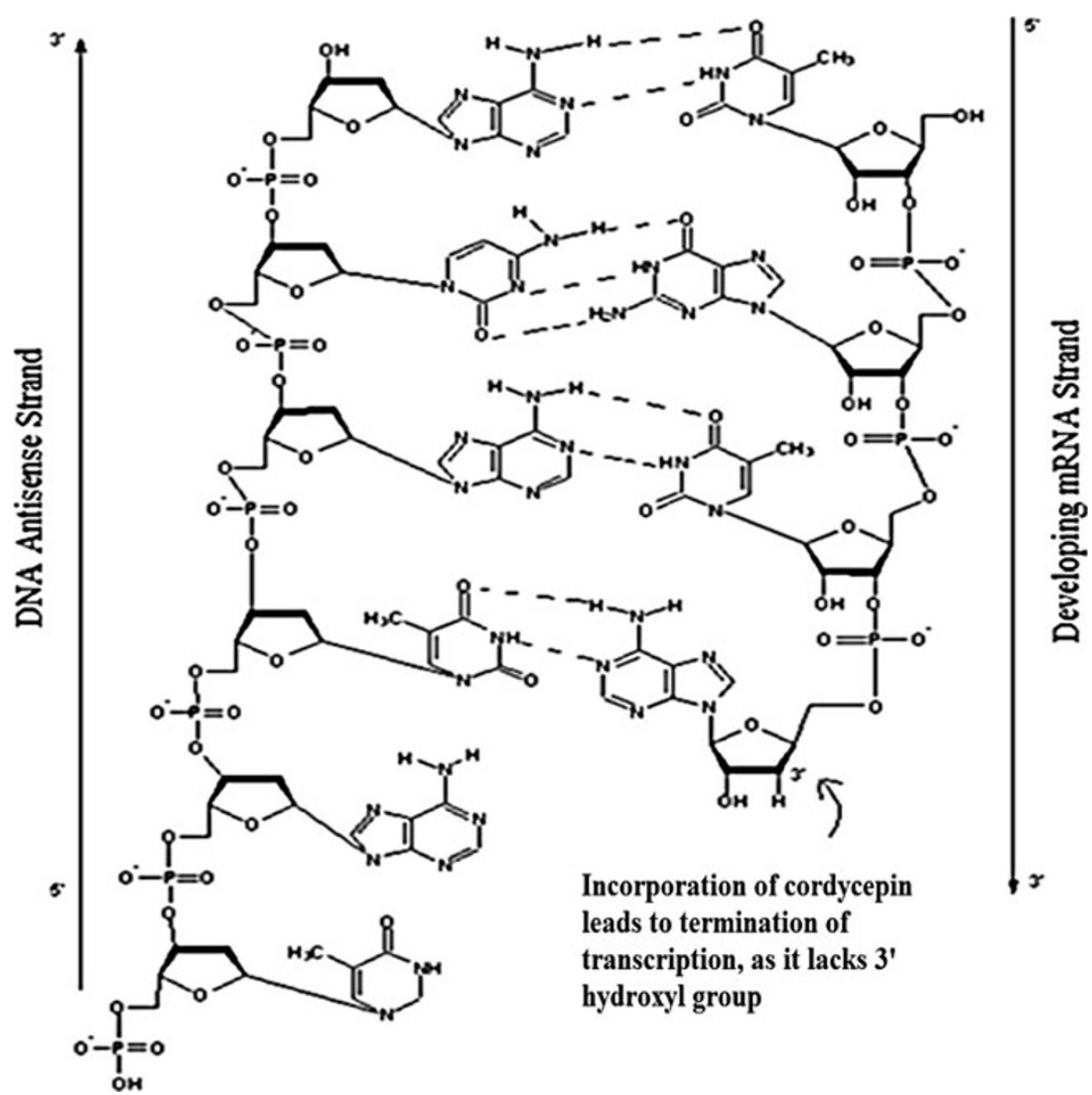

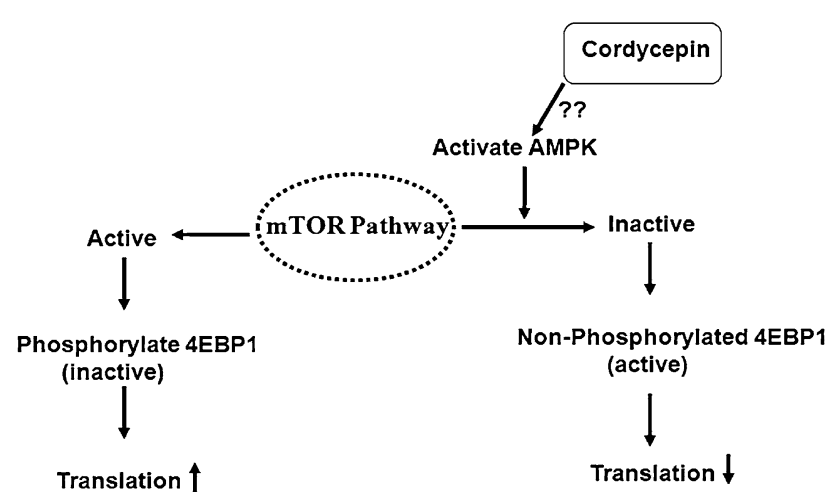

Fig. 4 Cordycepin presumably activates the AMPK by some unknown mechanism which further negatively regulates the translation of mTOR signaling transduction pathway by the formation of a translational repressor, 4-E-binding protein-1 (4EBP1)

role in infection to the host. These enzymes not only provide a penetration path to the conidia but also provide nutrition to the germinating conidia (Ali et al. 2010).

Further a short germ tube protruding out of the conidia starts thickening at the distal end which is known as appressorium. This appressorium maintains a kind of mechanical pressure on the germinating germ tube further improving the penetration effect of germ tube so as to reach into the insect's haemolymph (Hajek and Leger 1994). As the germ tube penetrates the epicuticle layer of insect's integument, it starts forming a plate-like structure called penetration plate. The penetration plate further produces secondary hyphae, which cross the epidermal layer and reach into the haemocoel of insect's body. From these hyphae, protoplast bodies bud off and start circulating into the insect's haemocoel. Fungus now starts growing into a filamentous mode invading internal organs and tissues of the host. During growth inside the host, fungus produces various kinds of toxic secondary metabolites, which are insecticidal. These secondary metabolites take the insect to its final life stage and ultimately insect dies out. Fungal mycelium emerges out through the cuticle and lead to the formation of fruiting body under suitable environmental conditions (Webster 1980). Morphological features of fruiting body include stipitate, yellowish-orange to orange to reddish-orange fruiting stroma which is cylindrical to slightly clavate in shape. Stipes of 1.5 - to $3-\mathrm{mm}$ thickness with fertile clava terminal (2.0- to $6.0-\mathrm{mm}$ wide) are also commonly seen in the fruiting body with overall stroma of about 1.5- to $7.0-\mathrm{cm}$ tall which can vary in length depending on the size of the host.

\section{Cordyceps diversity and cultivation}

There are more than 1,200 entomopathogenic fungi reported (Humber 2000) in the literature out of which the 
Cordyceps constitutes one of the largest genus containing approximately 500 species and varieties (Hodge et al. 1998; Hywel 2002; Muslim and Rahman 2010). Many different species of Cordyceps are being cultivated for their medicinal and pharmaceutical properties including $O$. sinensis, C. militaris, C. ophioglossoides, C. sobolifera, C. liangshanesis, and C. cicadicola. Similarly many other species of Cordyceps have been documented like C. tuberculata, C. subsessilis, C. minuta, C. myrmecophila, C. Canadensis, C. agriota, C. gracilis, C. ishikariensis, C. konnoana, C. nigrella, C. nutans, C. pruinosa, C. scarabaeicola, $C$. sphecocephala, $C$. tricentri, etc., although the molecular evidence for their proper phylogenetic placement is still lacking (Shrestha and Sung 2005; Wang et al. 2008; Zhou et al. 2009).

Nearly $80-85 \%$ of all medicinal mushroom products are extracted from their fruiting bodies while only $15 \%$ are derived from mycelium culture (Lindequist et al. 2005). Fruiting body of Cordyceps is a very small blade-like structure, making its collection difficult and expensive. Since there is a huge requirement of medicinal mushroom bio-metabolites, it is necessary to cultivate mycelium biomass artificially for which variety of methods for its cultivation have been proposed by many research groups (Masuda et al. 2006; Das et al. 2008, 2010a). Cordyceps mycelium can grow on different nutrients containing media, but for commercial fermentation and cultivation, insect larvae (silkworm residue) and various cereal grains have been used in the past. It has been seen consistently that from both insect larvae and cereal grains, fruiting body of fungus can be obtained with almost comparable medicinal properties (Holliday et al. 2004).

There are basically two fermentation techniques by which the cultivation of mycelium biomass of Cordyceps can be achieved including surface and submerged fermentation. In surface fermentation, the cultivation of microbial biomass occurs on the surface of liquid or solid substrate. This technique, however, is very cumbersome, expensive, labor intensive and rarely used at the industrial scale. While in submerged fermentation, micro-organisms are cultivated in liquid medium aerobically with proper agitation to get homogenous growth of cells and media components. However, there is a loss of extra-cellular compounds (after harvesting mycelium) from the broth which makes it necessary to improve the culture medium composition and downstream processing technology to get large-scale production of the secondary bio-metabolites ( $\mathrm{Ni}$ et al. 2009). It has been observed that the highest productivity can be achieved by repeated batch culture technique in which waste medium is removed at the end of the process and further refreshing the medium gives higher productivity of cells and bio metabolites.
Nutritional value of Cordyceps

In Cordyceps, there occurs a wide range of nutritionally important components including various types of essential amino acids, vitamins like B1, B2, B12 and $\mathrm{K}$, different kinds of carbohydrates such as monosaccharide, oligosaccharides and various medicinally important polysaccharides, proteins, sterols, nucleosides, and other trace elements (Hyun 2008; Yang et al. 2009, 2010; Li et al. 2011). In the fruiting body and in the corpus of $C$. militaris, the reported total free amino acid content is 69.32 and $14.03 \mathrm{mg} / \mathrm{g}$, respectively. The fruiting body harbors many abundant amino acids such as lysine, glutamic acid, proline and threonine as well. The fruiting body is also rich in unsaturated fatty acids (e.g., linoleic acid), which comprises of about $70 \%$ of the total fatty acids. There are differences in adenosine $(0.18$ and $0.06 \%)$ and Cordycepin $(0.97$ and $0.36 \%)$ contents between the fruiting body and the corpus, respectively (Hyun 2008).

\section{Bio-metabolites isolated from Cordyceps}

Cordyceps, especially its extract has been known to contain many biologically active compounds like Cordycepin, cordycepic acid, adenosine, exo-polysaccharides, vitamins, enzymes etc. (Table 1). Out of these, Cordycepin, i.e., 3'-deoxyadenosine (Fig. 1) isolated from ascomycetes fungus $C$. militaris, is the main active constituent which is most widely studied for its medicinal value having a broad spectrum biological activity (Cunningham et al. 1950).

\section{Cordycepin: mechanism of action}

The structure of Cordycepin is very much similar with cellular nucleoside, adenosine (Fig. 1) and acts like a nucleoside analogue.

Inhibition of purine biosynthesis pathway

Once inside the cell, Cordycepin gets converted into $5^{\prime}$ mono-, di- and tri-phosphates that inhibit the activity of enzymes like ribose-phosphate pyrophosphokinase and 5-phosphoribosyl-1-pyrophosphate amidotransferase which are used in de novo biosynthesis of purines (Fig. 2) (Klenow 1963; Overgaard 1964; Rottman and Guarino 1964).

\section{Cordycepin provokes RNA chain termination}

Cordycepin lacks $3^{\prime}$ hydroxyl group in its structure (Fig. 1), which is the only difference from adenosine. Adenosine is a nitrogenous base and acts as cellular nucleoside, which is needed for the various molecular processes in cells like synthesis of DNA and/or RNA. 
Table 1 Bioactive compounds isolated from Cordyceps sp.

\begin{tabular}{lll}
\hline S. no & Bioactive compounds & References \\
\hline 1 & Cordycepin & Cunningham et al. (1950) \\
2 & Cordycepic acid & Chatterjee et al. (1957) \\
3 & N-acetylgalactosamine & Kawaguchi et al. (1986) \\
4 & Adenosine & Guo et al. (1998) \\
5 & Ergosterol and & Yuan et al. (2007) \\
& ergosteryl esters & \\
6 & Bioxanthracenes & Isaka et al. (2001) \\
7 & Hypoxanthine & Huang et al. (2003) \\
8 & Acid deoxyribonuclease & Ye et al. (2004) \\
9 & Polysaccharide and & Yu et al. (2007, 2009), Xiao et al. \\
& exopolysaccharide & (2010), Yan et al. (2010) \\
10 & Chitinase & Lee and Min (2003) \\
11 & Macrolides $\left(\mathrm{C}_{10} \mathrm{H}_{14} \mathrm{O}_{4}\right)$ & Rukachaisirikul et al. (2004) \\
12 & Cicadapeptins and & Krasnoff et al. (2005) \\
& myriocin & \\
13 & Superoxide dismutase & Wanga et al. (2005) \\
14 & Protease & Hattori et al. (2005) \\
15 & Naphthaquinone & Unagul et al. (2005) \\
16 & Cordyheptapeptide & Rukachaisirikul et al. (2006) \\
17 & Dipicolinic acid & Watanabe et al. (2006) \\
18 & Fibrynolytical enzyme & Kim et al. (2006) \\
19 & Lectin & Jung et al. (2007) \\
20 & Cordymin & Wonga et al. (2011) \\
\hline & &
\end{tabular}

During the process of transcription (RNA synthesis), some enzymes are not able to distinguish between an adenosine and Cordycepin which leads to incorporation of $3^{\prime}$-deoxyadenosine or Cordycepin, in place of normal nucleoside preventing further incorporation of nitrogenous bases (A, $\mathrm{U}, \mathrm{G}$, and $\mathrm{C}$ ), leading to premature termination of transcription (Fig. 3) (Chen et al. 2008; Holbein et al. 2009).

\section{Cordycepin interferes in mTOR signal transduction}

Cordycepin has been reported to shorten the poly A tail of m-RNA which further affects its stability inside the cytoplasm. It was observed that inhibition of polyadenylation with Cordycepin of some m-RNAs made them more sensitive than the other mRNAs. At higher doses, Cordycepin inhibits cell attachment and reduces focal adhesion. Further increase in the dosage of Cordycepin may shutdown mTOR (mammalian target of rapamycin) signaling pathway (Fig. 4) (Wong et al. 2010). The name mTOR has been derived from the drug rapamycin, because this drug inhibits mTOR activity. The mTOR inhibitors such as rapamycin and CCI-779 have been tested as anti-cancer drugs, because they inhibit or block mTOR signaling pathway. mTOR is a $298 \mathrm{kDa}$ serine/threonine protein kinase from the family PIKK (Phosphatidylinositol 3-kinase-related kinase). The mTOR plays a very important role to regulate proteins synthesis. However, mTOR itself is regulated by various kinds of cellular signals like growth factors, hormones, nutritional environment, and cellular energy level of cells. As growth factors bind with cell receptor, Phosphatidyl inositol 3 kinase (PI3K) gets activated, converts phosphatidyl inositol bisphosphate (PIP2) to phosphatidyl inositol trisphosphate (PIP3). PIP3 further activates PDK1 (phosphoinositide dependent protein kinase 1). The activated PDK1 then phosphorylates AKT 1 kinase and makes it partially activated which is further made fully activated by mTORC 2 complex. The activated AKT 1 kinase now activates mTORC1 complex that leads to the phosphorylation of 4EBP1 (translational repressor) and makes it inactive, switching on the protein synthesis (Wong et al. 2010). The study confirmed that under low nutritional stress, Cordycepin activates AMPK which blocks the activity of mTORC1 and mTORC2 complex by some unknown mechanism. The inactivated mTORC2 complex cannot activate AKT 1 kinase fully, which in turn blocks mTOR signal transduction inhibiting translation and further cell proliferation and growth (Fig. 4).

\section{Molecular studies of genes isolated from Cordyceps sp.}

It is necessary to understand the genetic makeup and molecular biology of Cordyceps not only to enhance the production of Cordycepin and exopolysaccharides but also to figure out the biochemical synthetic pathway of the above bio-metabolites. Cordycepin and exopolysaccharides are some of the major pharmacologically active constituents of Cordyceps. There exists a variety of valuable genes encoding enzymes isolated and subsequently cloned from this medicinally important insect fungus. Isolation and cloning of FKS1 gene has been carried out successfully from Cordyceps which encodes for an integral membrane protein acting as a catalytic subunit for enzyme $\beta-1,3$ glucan synthase and responsible for the biosynthesis of a potent immunological activator, i.e., $\beta$-glucan (Ujita et al. 2006). Another group isolated Cu, Zn SOD 1 gene (SOD 1) from Cordyceps militaris which not only acts as an antioxidant and anti-inflammatory agent but also neutralizes free radicals which could be a potential anti-aging drug (Park et al. 2005). From Cordyceps sinensis, two cuticle degrading serine protease genes, i.e., csp 1 and csp 2 have been cloned and expressed in yeast Pichia pastoris. The genes, $c s p 1$ and $c s p 2$ were further characterized using synthetic substrate N-suc-AAPF-p-NA to understand the pathobiology and infection to the host (Zhang et al. 2008). Similar studies were carried out to clone and analyse glyceraldehyde-3-phosphate-dehydrogenase (GPD) gene from Cordyceps militaris. GPD is an important enzyme used in 
the glycolytic pathway, which catalyses the phosphorylation of glyceraldehyde-3-phosphate to form 1, 3-diphosphoglycerate, an important reaction to maintain life activities in a cell for the generation of ATP (Gong et al. 2009). Further studies could be directed toward improving Cordyceps sp. by developing an effective transformation system.

\section{Pharmaceutical and therapeutic potential of Cordyceps sp.}

Cordyceps species is also known as traditional Chinese medicine (TCM) as it has wide applications in pharmaceutical (Table 2) and health sector ( $\mathrm{Ng}$ and Wang 2005; Russell and Paterson 2008). This medicinal mushroom was in the limelight during the Chinese National Games in 1993, when a group of women athletes broke nine world records, committed that they had been taking Cordyceps regularly. It has been seen previously reported that Cordyceps also enhances physical stamina making it very useful for the elderly people and athletes. Recent literature further confirms that Cordyceps enhances cellular energy in the form of ATP (adenosine tri-phosphate). Upon hydrolysis of phosphates from ATP, lots of energy is released which is further used by the cell (Dai et al. 2001; Siu et al. 2004). The studies by many researchers in the past on Cordyceps have demonstrated that it has anti-bacterial, anti-fungal, larvicidal, anti-inflammatory, anti-diabetic, anti-oxidant, anti-tumor, pro-sexual, apoptotic, immunomodulatory, anti-HIV and many more activities (Table 2).

Cordyceps has a long history of use as a lung and kidney tonic, and for the treatment of chronic bronchitis, asthma, tuberculosis and other diseases of the respiratory system. The cardiovascular effects of Cordyceps are being noticed more frequently by researchers as it works through variety of possible ways either by lowering high blood pressure via direct dilatory effects or mediated through M-cholinergic receptors resulting in improvement in the coronary and cerebral blood circulation (Zhu et al. 1998b). Thus, Cordyceps has implications at the therapeutic level as well by rectifying the abnormalities in rhythmic contractions (also known as cardiac arrhythmia). Cordyceps extract has also been found as a promising source to increase cardiac output up to $60 \%$ in augmentation with conventional treatment of chronic heart failure (Chen 1995). The product from wild type and cultured Cordyceps has also been shown to significantly decrease blood viscosity and fibrinogen levels preventing myocardial infarction (Zhu et al. 1998b). Another study showed that the fermentation products of Cs-4 reduce myocardial oxygen consumption in animals under experimental lab conditions revealing dramatic anti-anoxic effects (Zhu et al. 1998a). These studies provide strong evidence that Cs- 4 and its fermentative solution prevent platelet aggregation stimulated by collagen or adenosine di-phosphate (ADP). An intravenous injection of concentrated Cordyceps extract $(90 \mu \mathrm{g} / \mathrm{kg}$ per min, i.v.) resulted in $51-71 \%$ reduction in ${ }^{51} \mathrm{Cr}$-labeled platelet aggregation in the endothelial abdominal aorta in rabbit (Zhu et al. 1998b).

\section{Toxicological and dosage related studies of Cordyceps}

Cordyceps is one of the best medicinal fungi known for numerous positive aspects in terms of pharmacological effects and considered to be safe. Some reports are published on its adverse gastrointestinal behaviors like dry mouth, nausea and diarrhea (Zhou et al. 1998). In some patients, allergic response has been seen during treatment with a strain of Cordyceps, i.e., CS-4 (Xu 1994). Patients, who suffer from autoimmune diseases such as rheumatoid arthritis, systemic lupus erythematosus and multiple sclerosis, are generally suggested to avoid its use. Reports are still lacking on pregnant and lactating women but some animal studies in mice have revealed that Cordyceps have effects on plasma testosterone levels (Huang et al. 2004; Wong et al. 2007). There has been couple of reports on lead poisoning in patients taking Cordyceps herbal medicine for treatment. The lead content in the Cordyceps powder in these cases was significantly high $(20,000 \mathrm{ppm})$ (Wu et al. 1996). However, the blood lead levels returned to normal upon termination of the product consumption.

Besides few negatively published data, Cordyceps is relatively considered to be a non-toxic medicinal mushroom. Cordyceps dose in patients suffering from long-term renal failure was demonstrated up to 3-6 g/day (Zhu et al. 1998b). In clinical studies involving lung cancer, chemotherapy was carried out with the combination of Cordyceps (Holliday and Cleaver 2008). In another clinical trial, results of Cordyceps ( $3.15 \mathrm{~g}$ for 5 weeks) were compared with placebo to evaluate its effects on physical performance (Parcell et al. 2004). In general, researchers demonstrated that 3-4.5 $\mathrm{g}$ of Cordyceps/day is sufficient except in patients suffering from severe liver disease (Mizuno 1999). However, no human toxicity report was found and even animal models were failed to determine median lethal dose. Cordyceps dosage up to $80 \mathrm{~g} / \mathrm{kg}$ body weight/day for 7 days was injected intraperitonealy in mice and even then it did not cause any fatality ( $\mathrm{Li}$ et al. 2006). In another study, rabbits fed through mouth for 3 months at a dose of $10 \mathrm{~g} / \mathrm{kg} /$ day did not show any deviancy in blood reports, or in kidney, liver functioning (Huang et al. 1987). Even water extract of Cordyceps sinensis was found to be nontoxic on macrophage cells line RAW264.7 proliferation 


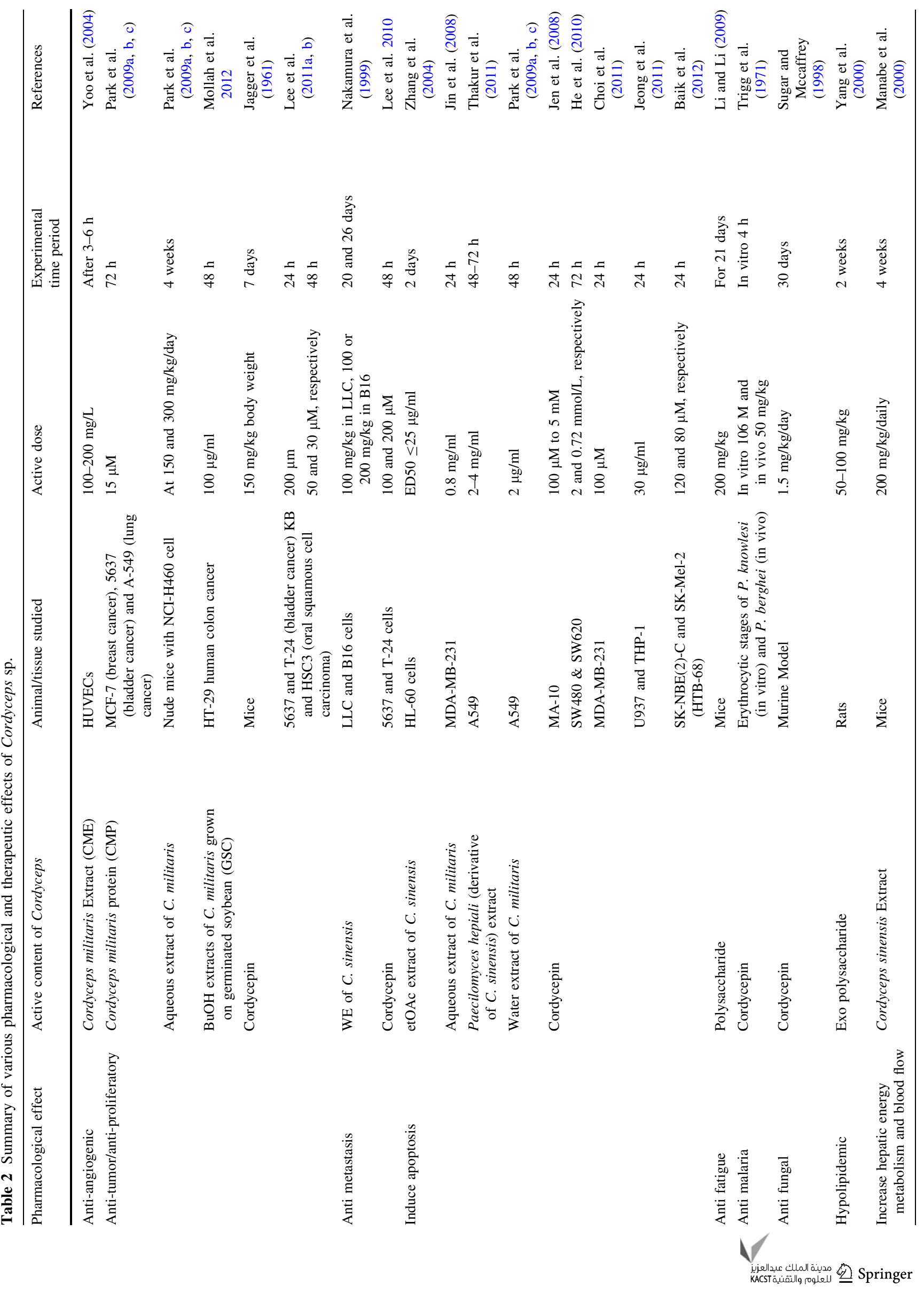




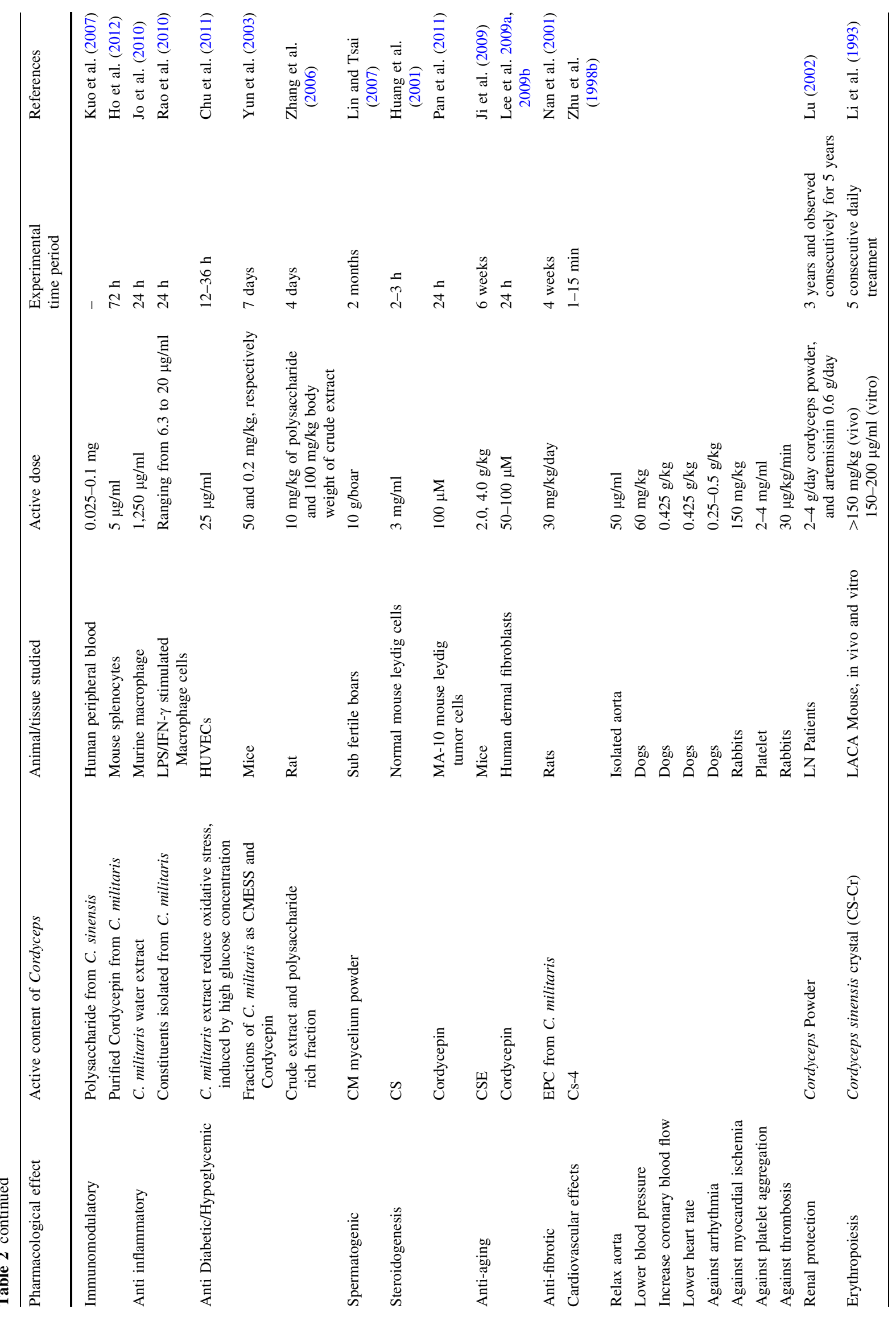




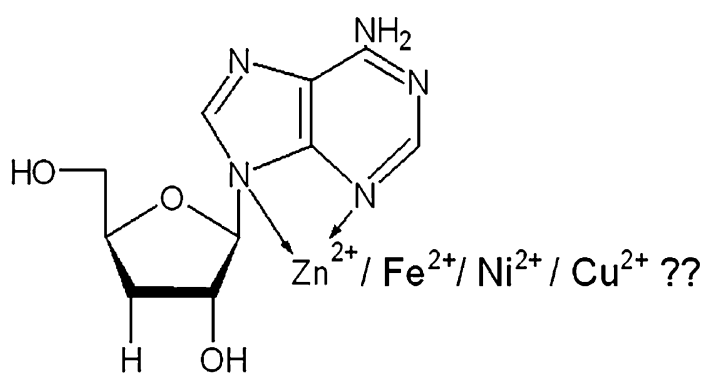

Fig. 5 Proposed metal complexes of Cordycepin which could be formed with various transition metals ion

(Mizuha et al. 2007). It is suggested that caution should be taken while taking Cordyceps by patients who are undergoing anti-viral or diabetic drug treatments as Cordyceps contains hypoglycemic and anti-viral agents, which can further affect the dosage of these drugs (Holliday and Cleaver 2008).

\section{Future perspective}

Cordyceps is a natural medicinal mushroom which is well liked by people nowadays as they believe more in natural therapy than chemotherapy because of lesser side effects. Growth characteristics of Cordyceps militaris have to be studied in-depth to cultivate this mushroom for its massscale production so that one could collect enough biometabolites from its mycelium extract. There is a strong urge to use interdisciplinary biotechnological and chemical tools to isolate and enhance the bioactivity of the metabolites from this entomopathogenic fungus. The structure of Cordycepin suggests that it has five $\mathrm{N}$ and three $\mathrm{O}$ atoms which one can imagine could form transition metal complexes in the form of di-, tri- and tetra-dentate ligands as metals can accommodate donor atom's lone pair of electrons into their empty $d$ orbital (Fig. 5). Complexity of the resulting compound and its molecular mass can be predicted with the help of spectroscopic tools like IR and mass spectroscopy, respectively, which can further improve the bioactivity of the compounds.

The remaining pharmacologically active compounds apart from Cordycepin also need to be identified and elucidate their structure-function relationship.

\section{Conclusions}

The usage of natural/herbal medicines over the synthetic ones has seen an upward trend in the recent past. Cordyceps being an ancient medicinal mushroom used as a crude drug for the welfare of mankind in old civilization is now a matter of great concern because of its unexplored potentials obtained by various culture techniques and being an excellent source of bioactive metabolites with more than 21 clinically approved benefits on human health including anti-diabetic, anti-tumor, anti-oxidative, immunomodulatory, sexual potentiator and anti-ageing effects (Das et al. 2010b). Cordycepin alone has been widely explored for its anti-cancer/anti-oxidant activities, thus, holding a strong pharmacological and therapeutic potential to cure many dreadful diseases in future. Further investigations need to be focused on to study the mechanistic insight into the mysterious potential of this medicinal mushroom on human health and promoting its cultivation strategies for commercialization and ethno-pharmacological use of this wonderful herb.

Open Access This article is distributed under the terms of the Creative Commons Attribution License which permits any use, distribution, and reproduction in any medium, provided the original author(s) and the source are credited.

\section{References}

Ali S, Ren S, Huang Z, Wu J (2010) Purification of enzymes related to host penetration and pathogenesis from entomopathogenic fungi. In: Mendez-Vilas A (ed) Current Research, Technology and Education Topics in Applied Microbiology and Microbial Biotechnology, Formatex Research Center, Spain, pp 15-22

Baik JS, Kwon HY, Kim KS, Jeong YK, Cho YS, Lee YC (2012) Cordycepin induces apoptosis in human neuroblastoma SK-N$\mathrm{BE}(2)-\mathrm{C}$ and melanoma SK-MEL-2 cells. Indian J Biochem Biophys 49:86-91

Borchers AT, Keen CL, Gershwin ME (2004) Mushroom, tumor, and immunity: an update. Exp Biol Med 229:393-406

Chatterjee R, Srinivasan KS, Maiti PC (1957) Cordyceps sinensis (Berkeley) saccardo: structure of cordycepic acid. J Am Pharm Assoc 46:114-122

Chen DG (1995) Effects of JinShuiBao capsule on the quality of life of patients with heart failure. J Admin Tradit Chin Med 5:40-43

Chen LS, Stellrecht CM, Gandhi V (2008) RNA-directed agent, cordycepin, induces cell death in multiple myeloma cells. Brit J Haematol 140:391-682

Choi S, Lim MH, Kim KM, Jeon BH, Song WO, Kim TW (2011) Cordycepin-induced apoptosis and autophagy in breast cancer cells are independent of estrogen receptor. Toxicol Appl Pharmacol 257:165-173

Chu HL, Chien JC, Duh PD (2011) Protective effect of Cordyceps militaris against high glucose-induced oxidative stress in human umbilical vein endothelial cells. Food Chem 129:871-876

Cunningham KG, Manson W, Spring FS, Hutchinson SA (1950) Cordycepin, a metabolic product isolated from cultures of Cordyceps militaris (L.) Link. Nature 166:949-954

Dai G, Bao T, Xu C, Cooper R, Zhu JX (2001) CordyMax ${ }^{\mathrm{TM}}$ Cs-4 improves steady-state bioenergy status in mouse liver. J Altern Complem Med 7:231-240

Das SK, Masuda M, Hatashita M, Sakurai A, Sakakibara M (2008) A new approach for improving cordycepin productivity in surface liquid culture of Cordyceps militaris using high-energy ion beam irradiation. Lett Appl Microbiol 47:534-538

Das SK, Masuda M, Hatashita M, Sakurai A, Sakakibara M (2010a) Effect of inoculation on production of anti-cancer 
drug-cordycepin in surface liquid culture using Cordyceps militaris mutant: a minor factor may greatly affect the result. Indian J Biotechnol 9:427-430

Das SK, Masuda M, Sakurai A, Sakakibara M (2010b) Medicinal uses of the mushroom Cordyceps militaris: current state and prospects. Fitoterapia 81:961-968

Devkota S (2006) Yarsagumba [Cordyceps sinensis (Berk.) Sacc.]; traditional utilization in Dolpa district, western Nepal. Our Nat 4:48-55

Gong Z, Su Y, Huang L, Lin J, Tang K, Zhou X (2009) Cloning and analysis of glyceraldehyde-3-phosphate dehydrogenase gene from Cordyceps militaris. Afr J Agr Res 4:402-408

Gu YX, Wang ZS, Li SX (2007) Effect of multiple factors on accumulation of nucleosides and bases in Cordyceps militaris. Food Chem 102:1304-1309

Guo C, Zhu J, Zhang C, Zhang L (1998) Determination of adenosine and $3^{\prime}$-deoxyadenosine in Cordyceps militaris (L.) Link by HPLC. Chin J Chinese Materia Medica 23:236-243

Hajek AE, Leger RJS (1994) Interactions between fungal pathogens and insects hosts. Annu Rev Entomol 39:293-322

Hattori M, Isomura S, Yokoyama E, Ujita M, Hara A (2005) Extracellular trypsin-like protease produced by Cordyceps militaris. J Biosci Bioeng 100:631-636

He W, Zhang MF, Ye J, Jiang TT, Fang X, Song Y (2010) Cordycepin induces apoptosis by enhancing JNK and p38 kinase activity and increasing the protein expression of $\mathrm{Bcl}-2$ proapoptotic molecules. J Zhejiang Univ Sci B 11:654-660

Ho JM, Seo MJ, Park JU, Kang BW, Kim KS, Lee JY, Kim GY, Kim JI, Choi YH, Kim KH, Jeong YK (2012) Effect of cordycepin purified from Cordyceps militaris on Th1 and Th2 cytokines in mouse splenocytes. J Microbiol Biotechnol 22:1161-1164

Hodge KT, Humber RA, Wozniak CA (1998) Cordyceps variabilis and the genus Syngliocladium. Mycologia 90:743-753

Holbein S, Wengi A, Decourty L, Freimoser FM, Jacquier A, DichtlrnaI B (2009) Cordycepin interferes with $3^{\prime}$ end formation in yeast independently of its potential to terminate RNA chain elongation. RNA 15:837-849

Holliday J, Cleaver M (2008) Medicinal value of the caterpillar fungi species of the genus Cordyceps (Fr.) Link (Ascomycetes): a review. Int J Med Mushrooms 10:219-234

Holliday J, Cleaver P, Powers ML, Patel D (2004) Analysis of quality and techniques for hybridization of medicinal fungus Cordyceps sinensis. Int J Med Mushrooms 6:147-160

Huang Y, Lu J, Zhu B, Wen Q, Jia F, Zeng S, Chen T, Li Y, Cheng G, Yi Z (1987) Toxicity study of fermentation Cordyceps mycelia B414. Chin Tradit Pat Med 10:24-25

Huang BM, Hsua CC, Tsai SJ, Sheu CC, Leu SF (2001) Effects of Cordyceps sinensis on steroidogenesis in normal mouse Leydig cells. Life Sci 69:2593-2602

Huang LF, Liang YZ, Guo FQ, Zhou ZF, Cheng BM (2003) Simultaneous separation and determination of active components in Cordyceps sinensis and Cordyceps militaris by LC/ESI-MS. J Pharm Biomed Anal 33:1155-1162

Huang YL, Leu SF, Liu BC, Sheu CC, Huang BM (2004) In vivo stimulatory effect of Cordyceps sinensis mycelium and its fractions on reproductive functions in male mouse. Life Sci 75:1051-1062

Humber RA (2000) Fungal pathogens and parasites of insects. In: Priest F, Goodfellow M (eds) Applied microbial systematics. Kluwer Academic Publishers, Dordrecht, pp 203-230

Hyun H (2008) Chemical ingredient of Cordyceps militaris. Mycobiology 36:233-235

Hywel NLJ (2002) Multiples of eight in Cordyceps ascospores. Mycol Res 106:2-3

Isaka M, Kongsaeree P, Thebtaranonth Y (2001) Bioxanthracenes from the insect pathogenic fungus Cordyceps pseudomilitaris
BCC 1620. II. Structure elucidation. J Antibiot (Tokyo) 54:36-43

Jagger DV, Kredich NM, Guarino AJ (1961) Inhibition of Ehrlich mouse ascites tumor growth by cordycepin. Cancer Res 21:216-220

Jen CY, Lin CY, Huang BM, Leu SF (2008) Cordycepin induced MA-10 mouse leydig tumor cell apoptosis through Caspase-9 Pathway. Evid Based Complement Alternat Med 2011:1-11

Jeong JW, Jin CY, Park C, Hong SH, Kim GY, Jeong YK, Lee JD, Yoo YH, Choi YH (2011) Induction of apoptosis by cordycepin via reactive oxygen species generation in human leukemia cells. Toxicol In Vitro 25:817-824

Ji DB, Ye J, Li CL, Wang YH, Zhao J, Cai SQ (2009) Anti-aging effect of Cordyceps sinensis extract. Phytother Res 23:116-122

Jin Yun C, Kim GY, Choi YH (2008) Induction of apoptosis by aqueous extract of Cordyceps militaris through activation of caspases and inactivation of Akt in human breast cancer MDAMB-231 cells. J Microbiol Biotechnol 18:1997-2003

Jo WS, Choi YJ, Kim HJ, Lee JY, Nam BH, Lee JD, Lee SW, Seo SY, Jeong MH (2010) The anti-inflammatory effects of water extract from Cordyceps militaris in murine macrophage. Mycobiology 38:46-51

Jung EC, Kim KD, Bai CH, Kim JC, Kim DK, Kim HH (2007) A mushroom lectin from ascomycete Cordyceps militaris. BBAGen Subj 1770:833-841

Kawaguchi N, Ohmori T, Takeshita Y, Kawanishi G, Katayama S, Yamada H (1986) Occurrence of Gal beta (1-3) GalNAc-Ser/Thr in the linkage region of polygalactosamine containing fungal glycoprotein from Cordyceps ophioglossoides. Biochem Biophys Res Commun 140:350-356

Kim JS, Sapkota K, Park SE, Choi BS, Kim S, Nguyen TH, Kim CS, Choi HS, Kim MK, Chun HS, Park Y, Kim SJ (2006) A fibrinolytic enzyme from the medicinal mushroom Cordyceps militaris. J Microbiol 44:622-631

Klenow H (1963) Formation of the mono-, di- and triphosphate of cordycepin in Ehrlich ascites-tumor cells in vitro. Biochim Biophys Acta 76:347-353

Krasnoff SB, Reategui RF, Wagenaar MM, Gloer JB, Gibson DM (2005) Cicadapeptins I and II: new Aib-containing peptides from the entomopathogenic fungus Cordyceps heteropoda. J Nat Prod 68:50-55

Kuo MC, Chang CY, Cheng TL, Wu MJ (2007) Immunomodulatory effect of exo-polysaccharides from submerged cultured Cordyceps sinensis: enhancement of cytokine synthesis, CD11b expression, and phagocytosis. Appl Microbiol Biotechnol 75: 769-775

Lee KH, Min TJ (2003) Purification and characterization of a chitinase in culture media of Cordyceps militaris (L.) Link. Korean J Med Mycol 31:168-174

Lee SJ, Kim SK, Choi WS, Kim WJ, Moon SK (2009a) Cordycepin causes p21WAF1-mediated G2/M cell-cycle arrest by regulating c-Jun N-terminal kinase activation in human bladder cancer cells. Arch Biochem Biophys 490:103-109

Lee YR, Noh EM, Jeong EY, Yun SK, Jeong YJ, Kim JY, Kwon KB, Kim BS, Lee SH, PPark CS, Kim JS (2009b) Cordycepin inhibits UVB-induced matrix metalloproteinase expression by suppressing the NF- $\kappa \mathrm{B}$ pathway in human dermal fibroblasts. Exp Mol Med 41:548-554

Lee EJ, Kim WJ, Moon SW (2010) Cordycepin suppresses TNFalpha-induced invasion, migration and matrix metalloproteinase9 expression in human bladder cancer cells. Phytother Res 24:1755-1761

Lee B, Park J, Park J, Shin HJ, Kwon S, Yeom M, Sur B, Kim S, Kim M, Lee H, Yoon SH, Hahm DH (2011a) Cordyceps militaris improves neurite outgrowth in neuro2A cells and reverses memory impairment in rats. Food Sci Biotechnol 20:1599-1608 
Lee JH, Hong SM, Yun JY, Myoung H, Kim MJ (2011b) Anti-cancer effects of cordycepin on oral squamous cell carcinoma proliferation and apoptosis in vitro. J Cancer Ther 2:224-234

Leger RJS, Bidochka MJ, Staples RC (1991) Preparation events during infection of host cuticle by Metarhizium anisopliae. J Invertebr Pathol 58:168-179

Li T, Li W (2009) Impact of polysaccharides from Cordyceps on antifatigue in mice. Sci Res Essays 4:705-709

Li Y, Chen GZ, Jiang DZ (1993) Effect of Cordyceps sinensis on erythropoiesis in mouse bone marrow. Chinese Med J 106:313316

Li SP, Yang FQ, Tsim KW (2006) Quality control of Cordyceps sinensis, a valued traditional Chinese medicine. J Pharm Biomed Anal 41:1571-1584

Li S, Li P, Ji H (2011) RP-HPLC determination of ergosterol in natural and cultured Cordyceps. Chin J Mod Appl Pharm 18:297-299

Lin WH, Tsai MT (2007) Improvement of sperm production in subfertile Boars by Cordyceps militaris supplement. Am J Chinese Med 35:631-641

Lindequist U, Niedermeyer THJ, Julich WD (2005) The pharmacological potential of mushrooms. Evid Based Complement Alternat Med 2:285-299

Lu L (2002) Study on effect of Cordyceps sinensis and artemisinin in preventing recurrence of lupus nephritis. Chin J Integr Med 22:169-171

Mains EB (1958) North American entomogenous species of Cordyceps. Mycologia 50:169-222

Manabe N, Azuma Y, Sugimoto M, Uchio K, Miyamoto M, Taketomo N, Tsuchita H, Miyamoto H (2000) Effects of the mycelial extract of cultured Cordyceps sinensis on in vivo hepatic energy metabolism and blood flow in dietary hypoferric anaemic mice. Br J Nutr 83:197-204

Masuda M, Urabe E, Sakurai A, Sakakibara M (2006) Production of cordycepin by surface culture using the medicinal mushroom Cordyceps militaris. Enzyme Microb Tech 39:641-646

Mizuha Y, Yamamoto H, Sato T, Tsuji M, Masuda M, Uchida M, Sakai K, Taketani Y, Yasutomo K, Sasaki H, Takeda E (2007) Water extract of Cordyceps sinensis (WECS) inhibits the RANKL-induced osteoclast differentiation. Biol Factors 30:105-116

Mizuno T (1999) Medicinal effects and utilization of Cordyceps (Fr.) Link (Ascomycetes) and Isaria Fr. (Mitosporic fungi) Chinese caterpillar fungi, "Tochukaso" (review). Int J Med Mushrooms $1: 251-262$

Mollah ML, PPark DK, Park HJ (2012) Cordyceps militaris grown on germinated soybean induces $\mathrm{G} 2 / \mathrm{M}$ cell cycle arrest through downregulation of Cyclin B1 and Cdc25c in human colon cancer HT-29 cells. Evid Based Complement Alternat Med 2012:1-7

Muslim N, Rahman H (2010) A possible new record of Cordyceps species from Ginseng Camp, Maliau Basin, Sabah, Malaysia. JTBC 6:39-41

Nakamura K, Yamaguchi Y, Kagota S, Kwon YM, Shinozuka K, Kunitomo M (1999) Inhibitory effect of Cordyceps sinensis on spontaneous liver metastasis of lewis lung carcinoma and B16 melanoma cells in syngeneic mice. Jpn J Pharmacol 79:335-341

Nan JX, Park EJ, Yang BK, Song CH, Ko G, Sohn DH (2001) Antifibrotic effect of extracellular biopolymer from submerged mycelial cultures of Cordyceps militaris on liver fibrosis induced by bile duct ligation and scission in rats. Arch Pharm Res 24:327-332

Negi CS, Koranga PR, Ghinga HS, Gumba (2006) Yar tsa (Cordyceps sinensis): A call for its sustainable exploitation. Int J Sust Dev World 13:1-8

Ng TB, Wang HX (2005) Pharmacological actions of Cordyceps, a prized folk medicine. J Pharm Pharmacol 57:1509-1519
Ni H, Zhou XH, Li HH, Huang WF (2009) Column chromatographic extraction and preparation of cordycepin from Cordyceps militaris waster medium. J Chromatogr B 877:2135-2141

Overgaard KH (1964) The inhibition of 5-phosphoribosyl-1-pyrophosphate formation by Cordycepin triphosphate in extracts of Ehrlich ascites tumor cells. Biochim Biophys Acta 80:504-507

Pan BS, Lin CY, Huang BM (2011) The effect of cordycepin on steroidogenesis and apoptosis in MA-10 mouse leydig tumor cells. Evid Based Complement Alternat Med 2011:1-14

Panda AK, Swain KC (2011) Traditional uses and medicinal potential of Cordyceps sinensis of Sikkim. J Ayurveda Integr Med 2:9-13

Parcell AC, Smith JM, Schulthies SS, Myrer JW, Fellingham G (2004) Cordyceps Sinensis (CordyMax Cs-4) supplementation does not improve endurance exercise performance. Int J Sport Nutr Exerc Metabol 14:236-242

Park NS, Lee KS, Sohn HD, Kim DH (2005) Molecular cloning, expression, and characterization of the $\mathrm{Cu}, \mathrm{Zn}$ superoxide dismutase (SOD1) gene from the entomopathogenic fungus Cordyceps militaris. Mycologia 97:130-138

Park BT, Na KH, Jung EC, Park JW, Kim HH (2009a) Anti-fungal and -cancer activities of a protein from the mushroom Cordyceps militaris. Korean J Physiol Pharmacol 13:49-54

Park SE, Kim J, Lee YW, Yoo HS, Cho CK (2009b) Antitumor activity of water extracts from Cordyceps militaris in NCI-H460 cell xenografted nude mice. J Acupunct Meridian Stud 2:294-300

Park SE, Yoo HS, Jin CY, Hong SH, Lee YW, Kim BW, Lee SH, Kim WJ, Cho CK, Choi YH (2009c) Induction of apoptosis and inhibition of telomerase activity in human lung carcinoma cells by the water extract of Cordyceps militaris. Food Chem Toxicol 47:1667-1675

Patel S, Goyal A (2012) Recent developments in mushrooms as anticancer therapeutics: a review. 3 Biotech 2:1-15

Rao YK, Fang SH, Wu WS, Tzeng YM (2010) Constituents isolated from Cordyceps militaris suppress enhanced inflammatory mediator's production and human cancer cell proliferation. J Ethnopharmacol 131:363-367

Rottman F, Guarino AJ (1964) The inhibition of phosphoribosylpyrophosphate amidotransferase activity by cordycepin mono phosphate. Biochim Biophys Acta 89:465-472

Rukachaisirikul V, Pramjit S, Pakawatchai C, Isaka M, Supothina S (2004) 10- membered macrolides from the insect pathogenic fungus Cordyceps militaris BCC 2816. J Nat Prod 67:1953-1958

Rukachaisirikul V, Chantaruk S, Tansakul C, Saithong S, Chaicharernwimonkoon L, Pakawatchai C, Isaka M, Intereya K (2006) A cyclopeptide from the insect pathogenic fungus Cordyceps sp. BCC 1788. J Nat Prod 69:305-307

Russell R, Paterson M (2008) Cordyceps-a traditional Chinese medicine and another fungal therapeutic biofactory? Phytochem 69:1469-1495

Sharma S (2004) Trade of Cordyceps sinensis from high altitudes of the Indian Himalaya: conservation and biotechnological priorities. Curr Sci 86:1614-1619

Shrestha B, Sung JM (2005) Notes on Cordyceps species collected from the central region of Nepal. Mycobiology 33:235-239

Singh N, Pathak R, Singh AK, Rautela D, Dubey A (2010) Collection of Cordyceps sinensis (Berk.) Sacc. in the interior villages of Chamoli district in Garhwal Himalaya (Uttarakhand) and its social impacts. J Am Sci 6:5-9

Siu KM, Mak HFD, Chiu PY, Poon KTM, Du Y, Ko KM (2004) Pharmacological basis of 'Yin-nourishing' and 'Yang-invigorating' actions of Cordyceps, a Chinese tonifying herb. Life Sci 76:385-395

Sugar AM, Mccaffrey RP (1998) Antifungal activity of 3'-deoxyadenosine (cordycepin). Antimicrob Agents Chemother 42:1424-1427

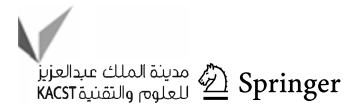


Thakur A, Hui R, Hongyan Z, Tian Y, Tianjun C, Mingwei C (2011) Pro-apoptotic effects of Paecilomyces hepiali, a Cordyceps sinensis extract on human lung adenocarcinoma A549 cells in vitro. J Can Res and Ther 7:421-426

Trigg P, Gutteridge WE, Williamson J (1971) The effect of Cordycepin on malarial parasites. T Roy Soc Trop Med H 65:514-520

Ujita M, Katsuno Y, Suzuki K, Sugiyama K, Takeda E, Yokoyama E, Hara A (2006) Molecular cloning and sequence analysis of the beta-1,3-glucan synthase catalytic subunit gene from a medicinal fungus, Cordyceps militaris. Mycoscience 47:98-105

Unagul P, Wongsa P, Kittakoop P, Intamas S, Srikitikulchai P, Tanticharoen M (2005) Production of red pigments by the insect pathogenic fungus Cordyceps unilateralis BCC 1869. J Ind Microbiol Biot 32:135-140

Wang L, Zhang WM, Hu B, Chen YQ, Qu LH (2008) Genetic variation of Cordyceps militaris and its allies based on phylogenetic analysis of rDNA ITS sequence data. Fungal Divers 31:147-156

Wang ZM, Peng X, Lee KLD, Tang JCO, Cheung PCK, Wu JY (2011) Structural characterisation and immunomodulatory property of an acidic polysaccharide from mycelial culture of Cordyceps sinensis fungus Cs-HK1. Food Chem 125:637-643

Wanga Z, Heb Z, Lib S, Yuanb Q (2005) Purification and partial characterization of $\mathrm{Cu}, \mathrm{Zn}$ containing superoxide dismutase from entomogenous fungal species Cordyceps militaris. Enzyme Microb Tech 36:862-869

Watanabe N, Hattori M, Yokoyama E, Isomura S, Ujita M, Hara A (2006) Entomogenous fungi that produce 2, 6-pyridine dicarboxylic acid (dipicolinic acid). J Biosci Bioeng 102:365-373

Webster J (1980) Introduction to fungi, 2nd edn. Cambridge University Press, Cambridge, p 355

Winkler D (2008) 'Yartsa Gunbu (Cordyceps sinensis) and the fungal commodification of the rural economy in Tibet AR. Econ Bot 63:291-305

Winkler D (2010) Cordyceps sinensis - a precious parasitic fungus infecting Tibet. Field Mycol 11:60-67

Wong KL, So EC, Chen CC, Wu RS, Huang BM (2007) Regulation of steroidogenesis by Cordyceps sinensis mycelium extracted fractions with (hCG) treatment in mouse Leydig cells. Arch Androl 53:75-77

Wong YY, Moon A, Duffin R, Barthet-Barateig A, Meijer HA, Clemens MJ, de Moor CH (2010) Cordycepin inhibits protein synthesis and cell adhesion through effects on signal transduction. J Biol Chem 285:2610-2621

Wonga JH, Nga TB, Wangb H, Szec SCW, Zhangc KY, Lid Q, Lue X (2011) Cordymin, an antifungal peptide from the medicinal fungus Cordyceps militaris. Phytomedicine 18:387-392

Wu TN, Yang KC, Wang CM, Lai JS, Ko KN, Chang PY, Liou SH (1996) Lead poisoning caused by contaminated Cordyceps, a Chinese herbal medicine: two case reports. Sci Total Environ 182:193-195

Xiao JH, Xiao DM, Xiong Q, Liang ZQ, Zhong JJ (2010) Nutritional requirements for the hyperproduction of bioactive exopolysaccharides by submerged fermentation of the edible medicinal fungus Cordyceps taii. Biochem Eng J 49:241-249

Xu Y (1994) Drug allergy occurred in a patient after orally taken JinShuiBao capsule. Chin J Chinese Materia Medica 19:503

Yan JK, Li L, Wang ZM, Wu JY (2010) Structural elucidation of an exopolysaccharide from mycelia fermentation of a Tolypocladium sp. fungus isolated from wild Cordyceps sinensis. Carbohydr Polym 79:125-130

Yang BK, Ha JY, Jeong SC, Das S, Yun JW, Lee YS, Choi JW, Song $\mathrm{CH}$ (2000) Production of exo-polymers by submerged mycelial culture of Cordyceps militaris and its hypolipidemic effect. J Microbio Biotechnol 10:784-788
Yang FQ, Feng K, Zhao J, Li SP (2009) Analysis of sterols and fatty acids in natural and cultured Cordyceps by one-step derivatization followed with gas chromatography mass spectrometry. J Pharm Biomed Anal 49:1172-1178

Yang FQ, Li DQ, Feng K, Hu DJ, Li SP (2010) Determination of nucleotides, nucleosides and their transformation products in Cordyceps by ion-pairing reversed-phase liquid chromatography-mass spectrometry. J Chromatogr A 1217:5501-5510

Ye MQ, Hu Z, Fan Y, He L, Xia FB, Zou GL (2004) Purification and characterization of an acid deoxyribonuclease from the cultured mycelia of Cordyceps sinensis. J Biochem Mol Biol 37:466-473

Yoo HS, Shin JW, Cho JH, Son CG, Lee YW, Park SY, Cho CK (2004) Effects of Cordyceps militaris extract on angiogenesis and tumor growth. Acta Pharm Sinic 25:657-665

Yu RM, Yang W, Song LY, Yan CY, Zhang Z, Zhao Y (2007) Structural characterization and antioxidant activity of a polysaccharide from the fruiting bodies of cultured Cordyceps militaris. Carbohydr Polym 70:430-436

Yu R, Yin Y, Yang W, Ma W, Yang L, Chen X, Zhang Z, Ye B, Song L (2009) Structural elucidation and biological activity of a novel polysaccharide by alkaline extraction from cultured Cordyceps militaris. Carbohydr Polym 75:166-171

Yuan JP, Wang JH, Liu X, Kuang HC, Zhao SH (2007) Simultaneous determination of free ergosterol and ergosteryl esters in Cordyceps sinensis by HPLC. Food Chem 105:1755-1759

Yue K, Ye M, Zhou Z, Sun W, Lin X (2012) The genus Cordyceps: a chemical and pharmacological review. J Pharm Pharmacol. doi: 10.1111/j.2042-7158.2012.01601.x

Yun Y, Han S, Lee S, Ko S, Lee C, Ha N, Kim K (2003) Anti-diabetic effects of CCCA, CMESS, and cordycepin from Cordyceps militaris and the immune responses in streptozotocin- induced diabetic mice. Nat Prod Sci 9:291-298

Zaidman BZ, Yassin M, Mahajna J, Wasser SP (2005) Medicinal mushroom modulators of molecular targets as cancer therapeutics. Appl Microbiol Biotechnol 67:453-468

Zhang Q, Wu J, Hu Z, Zhang D (2004) Induction of HL-60 apoptosis by ethyl acetate extract of Cordyceps sinensis fungal mycelium. Life Sci 75:2911-2919

Zhang G, Huang Y, Bian Y, Wong JH, Ng TB, Wang H (2006) Hypoglycemic activity of the fungi Cordyceps militaris, Cordyceps sinensis, Triccholoma mongolicum, and Omphalia lapidescens in streptozotocin-induced diabetic rats. Appl Microbiol Biotechnol 72:1152-1156

Zhang Y, Liu X, Wang M (2008) Cloning, expression, and characterization of two novel cuticle-degrading serine proteases from the entomopathogenic fungus Cordyceps sinensis. Res Microbiol 159:462-471

Zhang XL, Cheng LB, Assaf SA, Phillips GO, Phillips AO (2012) Cordyceps sinensis decreases TGF-b1 dependent epithelial to mesenchymal transdifferentiation and attenuates renal fibrosis. Food Hydrocolloids 28:200-212

Zhou JS, Halpern G, Jones K (1998) The scientifi c rediscovery of an ancient Chinese herbal medicine: cordyceps sinensis. J Altern Complem Med 4:429-457

Zhou X, Luo L, Dressel W, Shadier G, Krumbiegel D, Schmidtke P, Zepp F, Meyer CU (2008) Cordycepin is an immunoregulatory active ingredient of Cordyceps sinensis. Am J Chin Med 36:967-980

Zhou X, Gong Z, Su Y, Lin J, Tang K (2009) Cordyceps fungi: natural products, pharmacological functions and developmental products. J Pharm Pharmcol 61:279-291

Zhu JS, Halpern GM, Jones K (1998a) The scientific rediscovery of an ancient Chinese herbal medicine: cordyceps sinensis: part I. J Altern Complem Med 4:289-303

Zhu JS, Halpern GM, Jones K (1998b) The scientific rediscovery of a precious ancient Chinese herbal regimen: Cordyceps sinensis: part II. J Altern Complem Med 4:429-457 